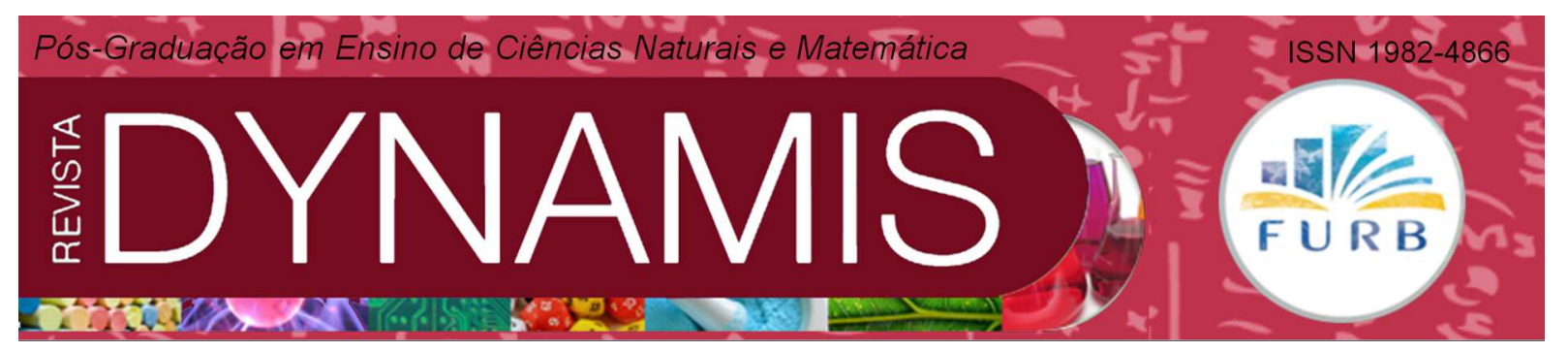

\title{
APRENDIZAGEM SIGNIFICATIVA NO ENSINO DE CIÊNCIAS: O SISTEMA LOCOMOTOR NO COTIDIANO DOS ESTUDATES
}

Grants meaningful learning in science teaching: locomotor system in daily life of students

Simony Suely Paes Souza

ICB-UFPA

simony@ufpa.br

Andre Ribeiro Santana

ICB-UFPA

mestredeo@yahoo.com.br

Luiza Nakayama

ICB-UFPA

lunaka@ufpa.br 


\title{
Resumo
}

O objetivo desta pesquisa foi descrever e avaliar qualitativamente as atividades sequenciais utilizadas no ensino do sistema locomotor, para estudantes de sétima série (atual 8 ano), tendo como motivações principais oportunizar aprendizagens significativas, contribuindo na superação de limitações do ensino tradicional. Programamos cinco momentos: 1. Distribuição dos ossos e músculos no molde do corpo humano; 2. Visita à Academia de Ginástica Z; 3. Aula ministrada na quadra de esportes da escola; 4. Releitura crítica do livro didático e 5. Produção de um CD-ROM. Concluímos que aulas planejadas na perspectiva da interdisciplinaridade propiciam uma aprendizagem significativa, quando levam em consideração conhecimentos prévios e nas quais os alunos têm a oportunidade de compartilhar dúvidas, opiniões e, literalmente, manusear neste processo, para construir respostas vinculadas às apreensões dos conteúdos abordados. Neste processo, é necessário que o professor esteja atento, avaliando os alunos em todos os momentos e fazendo autorreflexão, a fim de aperfeiçoar competências e habilidades.

Palavras-chave: Sistema músculo-esquelético. Atividades investigativas. Ensinoaprendizagem.

\begin{abstract}
The aim of this study was to describe and to evaluate qualitatively the sequential activities used for teaching the locomotor system to Middle School students (13 years old), in order to engender a way of learning that is more meaningful for the apprentices, thus contributing to overcome limitations in traditional teaching methods. We programmed five steps: 1 . Distribution of bones and muscles in the mold of the human body; 2. Visit to Gym Z; 3. Class given in the sports court of the school; 4. Critical rereading of the textbook and 5. Production of a CDROM. We conclude that interdisciplinary classes result in more significant learning, when they take into consideration previous knowledge, and in which students have the opportunity to share doubts, opinions, and literally use their own hands in the process, for the purpose of construing answers that are connected to the topic. During this process, it is necessary for the teacher to be alert, aiding the students in every moment and making auto-evaluation, as to improve skills and abilities.
\end{abstract}

Keywords: Musculoskeletal system. Investigative activities. Teaching and learning. 


\section{INTRODUÇÃO}

Para Ausubel (2003) há dois tipos antagônicos de aprendizagem: a mecânica e a significativa. Na primeira, os conhecimentos são adquiridos aleatoriamente, pelo exercício de repetição e memorização, já na segunda, um novo conhecimento é assimilado quando há uma interação entre a nova informação (conceitos, ideias) e os conhecimentos prévios, existentes na estrutura cognitiva do estudante.

Atualmente, a influência do Construtivismo no processo de ensino-aprendizagem está cada vez mais frequente. Neste contexto, a prioridade é que o aluno aprenda a ter autonomia na aquisição de saberes: tenha a capacidade de selecionar, correlacionar, processar, interpretar e assimilar conhecimentos. Assim, para que a aprendizagem seja significativa, não se concebe mais a figura do professor como simples transmissor e do aluno como receptor de conhecimentos, e, sim, se valoriza a interação professor-aluno. No entanto, Massabni (2007, p. 10), analisando a prática pedagógica de quatro professores de Ciências, ressalta que há "elementos construtivistas e tradicionais, ao invés de uma 'prática construtivista' tal como imaginada pelos autores do Construtivismo". E conclui, na mesma página: "A mescla, quando observada nas aulas, significa que o professor seleciona, em sua prática, o que considera viável de um referencial construtivista para a escola, diante da realidade em que trabalha".

Meirieu (1998) aprofunda a reflexão sobre o ato de aprender e estabelecer referências a partir das quais o professor poderá elaborar, controlar e avaliar sua ação pedagógica. Analisa, no processo de ensino-aprendizagem, o triângulo pedagógico: educando-sabereducador e a relação pedagógica, racionalização didática e estratégias individuais de aprendizagem, salientando que aprendizagens significativas permitirão que o aluno, a partir de suas vivências, construa seus próprios mapas de conhecimento e verdades. Nesse aspecto, Saviani (2000) alerta que não é suficiente que o conteúdo programático seja apenas "ensinado", é necessário uni-lo de forma indissociável à sua significação humana e à realidade social concreta. Portanto, no processo de ensino-aprendizagem espera-se que o professor, atuando simultaneamente como orientador, coordenador e facilitador esteja alerta aos mecanismos de relações interpessoais ao interagir com o discente, sem perder de vista que a cooperação pedagógica deve se adequar às necessidades e às características de cada um de seus alunos.

Cabe ressaltar o questionamento de Fonseca e Nakayama (2010, p. 149), sobre a cultura cabocla amazônica que "tradicionalmente, a prática educativa está desvinculada dessa realidade e, portanto, pouco se utilizam das experiências de vida e dos elementos da cultura, para qualificar a ação pedagógica, quer seja em espaços escolares ou não escolares".

Neste contexto, o ensino de Ciências deve merecer atenção especial desde as séries iniciais, por vários motivos: a curiosidade inerente ao ser humano, de conhecer suas possibilidades e limitações e, também, suas interações com o meio ambiente; a oportunidade de proporcionar aprendizado, a qual propicia a criação de hábitos saudáveis (pessoais e coletivos) visando à melhoria de qualidade de vida; a possibilidade de refletir e adequar valores formativos, transferindo-os para outros contextos da vida cotidiana, gerados por uma sociedade com crescente desenvolvimento científico e tecnológico; a importância de formar cidadãos críticos possuidores de uma base de conhecimentos que lhes fundamentem tomar decisões diante de contextos científicos e tecnológicos, bem como participar ativamente da conservação e preservação do ambiente que integram (BRASIL, 2000, 2001; BUENO, 2003). Além disso, para os jovens "conhecer ciência é ampliar a sua possibilidade presente de participação social e viabilizar sua capacidade plena de participação social no futuro" (BRASIL, 2001, p. 25). 
Há consenso entre vários pesquisadores para que, no ensino de Ciências, os professores transcendam exposições teóricas, contextualizando suas práxis, inclusive ao ministrarem aulas práticas com experimentações e/ou outros recursos didáticos, visando oportunizar, de modo crítico e reflexivo, situações significativas de ensino e aprendizagens (KRASILCHIK, 1987; DELIZOICOV; ANGOTTI; PERNAMBUCO, 2002; CARVALHO; GIL-PÉREZ, 2003).

No entanto, devido a vários fatores alegados pelos professores, tais como: cumprimento de extensos conteúdos programáticos, baixa remuneração, falta de interesse dos alunos, dificuldade para realizar formação continuada docente, dentre outros (HENNIG, 1998; SOUZA, 2002; SOUZA; NAKAYAMA; BELÚCIO, 2003; SILVA et al., 2010; DANTAS; SANTANA; NAKAYAMA, 2012; SILVA; CONCEIÇÃO; SANTANA; NAKAYAMA, 2012), a escola acaba optando por um ensino no qual os professores ministram o conteúdo de forma expositiva, recorrendo aos livros didáticos, por vezes, como o único recurso pedagógico, que pouco ou nada favorece às situações de observação, reflexão e verbalização de apreensões, condições essenciais para aprendizagens significativas. É o que consideramos, genericamente, como Ensino Tradicional, no qual o conhecimento científico é apresentado como algo pronto e descontextualizado, cuja apropriação requer apenas exercícios de memorização, imitação ou repetição por parte dos alunos, sendo a prática experimental mera complementação ou estratégia de confirmação das teorias apresentadas pelos professores (BACHELARD, 1996; AMARAL, 1997; SILVA; ZANON, 2000; SANMARTÍ, 2002).

Nesta perspectiva, ensinar Ciências em uma realidade na qual os desafios aumentam de uma forma acelerada, diante das mudanças no âmbito do conhecimento, modificações envolvendo conteúdos a serem ministrados e métodos que viabilizem essa práxis, e também considerando, simultaneamente, especificidades discentes e demandas sociais, não é uma tarefa fácil para o professor (SANMARTÍ, 2002).

Como os métodos tradicionais, na maioria das vezes, não conseguem despertar o interesse do alunado e contribuem pouco para a construção de aprendizagens significativas, sugerimos, em uma perspectiva simultaneamente reflexiva e empírica, atividades práticas. Porém, levamos em consideração Silva e Zanon (2000), que partem do pressuposto que aulas práticas em Ciências não asseguram, por si só, promoções de aprendizagens significativas e não garantem o estabelecimento de relações entre teoria e prática. Essas autoras comentam que aulas restritas a atividades experimentais são comuns, ficando como tarefa a elaboração de um relatório que, em geral, prioriza procedimentos, materiais utilizados e observações, em detrimento às explicações e às significações teórico-conceituais propostas pelos/aos alunos. Nesse sentido, Krasilchik (2000) aponta dois extremos: de um lado, o docente se comportando como autoridade, para não correr riscos de sofrer questionamentos e nem ouvir opiniões diferentes; de outro lado, um consenso crescente de que o "aluno constrói seu próprio conhecimento" devendo o professor assumir funções de coordenador de aprendizagens. E conclui: "Nesses casos, o laboratório e as aulas práticas podem até ser divertidas, mas não levam à formulação ou reformulação de conceitos" (KRASILCHIK, 2000, p. 88).

Amaral (1997) ressalta que a experimentação pode conduzir a apreensões teóricas, desde que o professor atue como orientador do processo de investigação, promovendo situações de questionamentos e reflexões no alunado. Nesse contexto, Libâneo (2001) argumenta que um professor bem preparado para ministrar suas aulas transmitirá segurança ao seu alunado e conseguirá, inclusive, trabalhar o conteúdo de sua disciplina de forma prazerosa e com menos possibilidades de rejeição. 
Em um estudo anterior relatamos atividades investigativas sobre o corpo humano, induzindo alunos da sétima série ( $8^{\circ}$ ano, pela nova nomenclatura) a se perceberem como objeto de estudo, porém, na avaliação de aprendizagem prevaleceu primordialmente a análise quantitativa. Neste sentido, baseamos a investigação sobre o processo de ensino-aprendizagem do conteúdo sistema locomotor em prova escrita com questões objetivas, aplicadas aos alunos de sétima série e consideramos apenas as notas bimestrais. No entanto, sentimos que essa avaliação quantitativa foi insatisfatória, mecanicista e limitou as potencialidades dos alunos. Reconhecemos que prova escrita é a forma de avaliação mais comum no sistema tradicional de ensino, assim, o aumento crescente da média das notas serviu de estímulo, para propormos análise qualitativa do ensino-aprendizagem sobre Corpo Humano, em Ciências.

Neste contexto, o presente estudo foi concebido considerando a multidimensionalidade no processo de avaliação. Cabe ressaltar que sabemos que o conceito de avaliação é muito abrangente, permitindo investigar o desempenho discente a partir de aspectos qualitativos e quantitativos; e neste sentido nos apoiamos em Sousa (1994, p. 227) que, na avaliação, "o diagnóstico de dificuldades e facilidades não deve ser compreendido como um veredicto, mas sim, como uma análise da situação atual do educando, em função das condições de ensino que irão sendo oferecidas".

Portanto, tendo como premissa um modelo pedagógico no qual foram valorizadas as concepções prévias dos alunos e a prática experimental dirigida, realizamos as atividades investigativas, sem esquecer as flexibilidades do/no planejamento. Assim, tendo como motivação principal transcender limitações do ensino tradicional, o nosso objetivo foi descrever e avaliar qualitativamente as atividades sequenciais utilizadas no ensino do sistema locomotor, para estudantes de sétima série.

\section{CAMINHOS METODOLÓGICOS}

Apresentamos nossa proposta de ação a qual foi aprovada pela equipe gestora de uma instituição de ensino particular do município de Belém - PA. Em seguida, sorteamos a sétima série (turma 2004) e o conteúdo: "Sistema locomotor: conhecendo para saber como funciona". A classe era composta de 19 alunos (10 meninas e 9 meninos), com idade média de 13 anos.

Planejamos o cronograma de atividades sequenciais para as manhãs de sábado e as dividimos estas atividades em cinco momentos: o $1^{\circ}$ momento foi a distribuição hipotética dos ossos e músculos no molde do corpo humano; o $2^{\circ}$ foi a visita à Academia de Ginástica Z (o nome da Instituição foi resguardado por meio do uso de pseudônimo); o $3^{\circ}$ a aula ministrada na quadra de esportes da Escola, pelo professor de Educação Física; o $4^{\circ}$ releitura conjunta do livro didático e o $5^{\circ}$ a produção de um CD-ROM, com todos os conteúdos pesquisados ao longo do ano letivo, sobre o corpo humano. Para que os momentos fossem viabilizados, traçamos, com clareza, os objetivos de cada momento, o que facilitou a canalização das perguntas da turma e criou um clima de investigação, em que a curiosidade científica dos alunos foi incentivada. A fim de direcionar e instigar os alunos, partimos da questão norteadora: Qual a importância do Sistema Locomotor, para o corpo humano? A partir desta premissa, foram surgindo outras questões secundárias, durante as descobertas realizadas e rodas de conversas. Também, para cada momento, propusemos uma questão-problema, a fim de que os alunos pudessem direcionar suas observações, levantar hipóteses, fazer registros e tirar suas próprias conclusões. 
Cabe ressaltar que organizamos os cinco momentos, procurando atender ao passos sugeridos por Zylberztajn (1991), para aquisição de conhecimento: 1. A conscientização, por parte dos alunos, de suas concepções alternativas; 2. A comparação das ideias prévias com o pensamento científico, por meio de questões e de indagações; 3. A apresentação de novas ideias ou concepções científicas, com intuito de avaliar se o conhecimento construído se orientou nas ideias conceituais científicas apresentadas pelos livros didáticos e 4 . A tentativa, em desvendar o 'quebra-cabeça', a partir de esforços para solucionar os problemas propostos.

A valorização do diálogo e da autonomia dos alunos norteou as atividades, em todos os momentos, principalmente nas rodas de conversa "porque os sujeitos dialógicos não apenas conservam sua identidade, mas a defendem e assim crescem um com o outro. O diálogo, por isso mesmo, não nivela, não reduz um ao outro. [...]. Implica, ao contrário, um respeito aos sujeitos nele engajados". (FREIRE, 1993, p. 118).

Nos momentos pedagógicos propostos, realizamos a avaliação globalmente, como um processo de análise qualitativa contínua referente ao ensino e aprendizagem entre os alunos, sendo fruto de uma abordagem que envolveu, além do aluno, o ambiente escolar e, nós, os professores. Vasconcellos (1994, p. 43) destaca a avaliação como sendo "um processo abrangente da existência humana, que implica uma reflexão crítica sobre a prática, no sentido de captar seus avanços, suas resistências, suas dificuldades e possibilitar uma tomada de decisão sobre o que fazer para superar os obstáculos".

Nossa pesquisa tem caráter qualitativo, cabendo ressaltar que, de acordo com André e Lüdke (1986), esse tipo de pesquisa deve valorizar o contato direto e constante no cotidiano escolar. E dentro da pesquisa qualitativa, definimos nosso estudo como pesquisa-ação cujos princípios (MINAYO, 2002; THIOLLENT, 2005; TOZONI-REIS, 2007) guardam relações com transformações democráticas da realidade, entendida como movimento histórico, nunca com caráter de atemporalidade. Neste sentido, levamos em consideração vivências discentes e diversas modalidades de relações: aluno consigo mesmo, aluno-aluno e professor-aluno.

Assim, após cada momento e norteada pela premissa de Gatti (2003) de que observar com precisão e controle e de que mensurar são importantes critérios de cientificidade, solicitamos aos alunos que fizessem tabelas dos dados obtidos e resumo das suas impressões em cada momento, logo que fosse possível, e que apresentassem sugestões por escrito, visando reflexões e aprimoramento. Além disso, registramos em caderno de campo e em fotografias, nossas atividades e percepções.

Para interpretação dos dados obtidos, tomamos como base a análise de conteúdo, entendida como um conjunto de técnicas destinadas "à descoberta do que está por trás dos conteúdos manifestos, indo além das aparências do que está sendo comunicado" (MINAYO, 2002, p. 74).

\section{DESEMPENHOS OBSERVADOS/VIVENCIADOS DURANTE OS MOMENTOS}

No $1^{\mathrm{o}}$ momento, para verificarmos os conhecimentos prévios, os alunos desenharam, em papel $40 \mathrm{~kg}$, o contorno dos seus corpos e, em seguida, organizaram e distribuíram os ossos e os músculos no modelo. Cada equipe defendeu a construção do seu sistema locomotor (os mais variados desenhos: dos possíveis aos inimagináveis). Observamos que os alunos os quais praticavam algum tipo de esporte conseguiram mostrar uma construção um pouco mais precisa e organizada, destes elementos no corpo humano: "No karatê, caí de mal jeito e quebrei o 
braço. O médico me mostrou, na radiografia, o úmero, que é o osso do braço e também os ossos do antebraço: r rádio e o ulna"; "Nadando, tive câimbra na coxa, onde fica o fêmur, que é o maior osso do nosso corpo".

Os alunos que apresentaram a distribuição "errada", por não serem criticados, se sentiram mais à vontade para tirar as suas dúvidas. Dentre as quais: "[...] é por isso que a gente ficou de pé? Quando a gente passou a andar em pé nossa vida melhorou, até nosso corpo mudou, igual ao que o professor de História falou dos nossos ancestrais?" demonstrando que o aluno relacionou o sistema locomotor às argumentações históricas acerca da evolução humana.

Vale lembrar que, em todas as nossas ações e intervenções, trabalhamos o erro de modo diferenciado. Em consonância com Bachelard (1996) que não o considera como obstáculo aos processos de ensino e aprendizagem; acreditamos que pode propiciar momentos de orientações e reavaliações capazes de aprimorar os conhecimentos. Assim, os alunos entenderam que o erro pode ser fonte de reflexões e aperfeiçoamentos, durante construções de conhecimentos.

Neste sentido, o diálogo com os alunos foi com o objetivo de favorecer entendimentos abrangentes e não fragmentados do conteúdo programático. Em conformidade com diversos autores (FAZENDA, 1993; GIRARDELLI, 1999; BORDONI, 2002; BOVO, 2007) consideramos conhecimentos como construções vinculadas às subjetividades de seu tempo, portanto, a aprendizagem requer tanto apropriações dos seus elementos essenciais, quanto o reconhecimento das diversificadas influências, contextuais, presentes em sua estruturação. Aludindo à Perrenoud (2001), defendemos que as manifestações dos nossos alunos devem ser entendidas como oportunidades únicas, para detectarmos suas dúvidas, limitações, dificuldades e entendimentos efetivos. Neste contexto, Libâneo (2001) argumenta que um professor consciente das especificidades de seu ofício, bem preparado em termos epistemológicos e metodológi$\cos$, transmite veracidade de maneira natural, podendo, assim, pelo estabelecimento de confiança mútua entre ele e seus alunos, diversificar sua prática docente, sem excluir o diálogo e as ações pedagógicas pensadas, para favorecer o ensino e a aprendizagem.

$\mathrm{O} 2^{\circ}$ momento foi a visita à Academia de Ginástica Z, com acompanhamento de professores de outras disciplinas. A caminhada até o local já propiciou algumas indagações: desde a relação da academia com aula de Ciências, até outras mais direcionadas às reações do corpo frente aos exercícios físicos.

Os professores de Educação Física da academia abordaram noções básicas sobre o funcionamento do Sistema Locomotor, mostraram os aparelhos disponíveis e suas respectivas funções. Em seguida, com o acompanhamento de uma das professoras de ginástica, os alunos fizeram exercícios físicos, inicialmente fora e depois dentro da piscina. Na piscina, houve algumas manifestações: "Parece que não sinto muito cansaço quando estou na água!"; "Não dói tanto fazer exercícios aqui dentro!"; "É mais gostoso, é relaxante!". A explicação de um aluno para as novas sensações foi: "Ah! Eu acho que é porque o corpo fica leve, aí a gente sente menos o nosso peso". A partir de comentários como estes, percebemos a infinidade de temas que podem ser discutidos com os alunos, como por exemplo: a densidade e a força da gravidade sobre os corpos.

A participação na aula de hidroginástica, com um grupo da terceira idade, oportunizou aos alunos perceberem que ficaram mais cansados que as pessoas com mais idades. A professora de ginástica ressaltou que em qualquer esporte e idade, é necessário que a pessoa se prepare, cuidando da alimentação, do condicionamento físico e mental. 
Realizamos uma roda de conversa, na qual os alunos se manifestaram favoráveis por unanimidade à aula na Academia, como atestam estes depoimentos: "Professora, vou lhe falar: se eu estivesse só sentado ouvindo a senhora falar, a aula ia ficar chata, difícil de entender. Mas, assim, praticando, eu entendo tudo melhor."; "É engraçado, quando a gente sente e faz aquilo que o professor fala na aula, a gente entende melhor, fica mais fácil entender a matéria". Estes posicionamentos reforçam a observação de Buchweitz (2001) ao comentar que os alunos consideraram a aprendizagem como significativa, principalmente porque a atividade extraclasse representou aquisição de valores ou reflexos para mudança de comportamentos, ou, ainda, porque serviu para a aplicação de conhecimentos, em novas situações.

O $3^{\circ}$ momento foi a aula ministrada na quadra poliesportiva da Escola, pelo professor de Educação Física. Os alunos fizeram alongamentos, em seguida uma caminhada, uma corrida e, finalmente, uma breve partida de futebol.

Ao término do jogo, realizamos uma roda de conversa. O questionamento inicial foi sobre a importância da disciplina Educação Física na escola, o qual foi respondido adequadamente pela própria turma. O professor aproveitou para reforçar a necessidade de se empenhar individualmente nas atividades e de valorizar o trabalho em equipe, para conquistar as vitórias. O clima descontraído também permitiu que os alunos indagassem sobre o uso não só de anabolizantes, mas também de outras drogas e suas consequências. Portanto, constatamos que quanto mais se oportuniza atividades com a participação de toda a classe, nas quais todos podem expressar dúvidas e opiniões, mais favorecemos os próprios alunos a se reconhecerem como parte de um todo, assim, mais espontâneas são as manifestações positivas, para formação de uma consciência cidadã.

Observamos que o manuseio do "Juvenal" (um boneco que os alunos fizeram em papelão, com os órgãos e as estruturas internas individualizadas, encaixáveis com arames), neste momento, foi realizado com mais facilidade, pois desmontando e re-encaixando as peças do corpo do boneco, os alunos demonstraram estar percebendo, de forma mais concreta, a distribuição dos ossos e da musculatura no organismo.

Cabe informar que Biasotto e Gomes (2012), analisando posturas corporais de alunos da sétima série do Ensino Fundamental de uma escola pública, do Município de Araruna- PR, verificaram que a maioria possuía desvios na coluna (cifose, lordose e escoliose), sugerindo que se na disciplina de Educação Física fosse realizada a avaliação postural, como parte integrante de seus conteúdos, dificilmente o aluno recusaria a execução de exercícios apropriados, para melhorar a sua postura. Trata-se de conclusão que enfatiza a relevância da Educação Física no currículo escolar, algo reforçado ainda mais pelo argumento de Barni e Schneider (2007) de que esta disciplina pode propiciar o aprimoramento de atitudes socialmente desejáveis, tais como a autonomia, a sociabilidade, a cooperação e o espírito de equipe.

Consideramos que o enfoque interdisciplinar adotado nas aulas na academia e na quadra da escola contribuiu significativamente, no sentido de proporcionar aprendizagens e saberes a esta turma. Os alunos se sentiram estimulados por participarem de aulas, nas quais havia mais de um professor atuando nas atividades propostas, como atesta este depoimento: "Que legal! Gostei de ver! Professores trabalhando juntos, falando de várias coisas que a gente vê nas aulas". Toda essa situação evidencia a importância da interdisciplinaridade no processo de ensino-aprendizagem, algo enfatizado por autores como Fazenda (1993); Girardelli (1999) e Bordoni (2002).

No $4^{\circ}$ momento, analisamos como o sistema locomotor é apresentado no livro didático adotado na escola. Cabe ressaltar que Lajolo (1996) enfatiza que o uso dessa fonte de infor- 
mação não se deve restringir aos seus aspectos pedagógicos, mas também aos aspectos político e cultural, porque reproduz e representa os valores em relação a uma dada visão da ciência, da história, da interpretação dos fatos e do próprio processo de construção de conhecimento. Neste contexto, atualmente, a comunidade escolar tem à disposição, outras fontes e mesmo os Parâmetros Curriculares Nacionais (Brasil, 2000, 2001) recomendam que o professor utilize, como fonte de informação, além do livro didático, materiais diversificados (jornais, revistas, mídias virtuais, filmes, etc). Trata-se de sugestão cuja execução pode sensibilizar o discente a buscar espontaneamente se informar, de modos diversificados, na/sobre a realidade que integra.

Assim, para esclarecer dúvidas e obter informações adicionais, conjuntamente com os alunos, consultamos o acervo disponível na biblioteca da escola e os materiais trazidos pelos alunos; também acessamos a internet e utilizamos anotações prévias dos alunos (obtidas nos três momentos anteriores). No final, construímos reflexões e questões, com as possíveis discussões e respostas.

Neste processo, em relação ao livro didático por eles utilizado, os alunos constataram que: 1 . O corpo humano foi apresentado parecendo uma "tela pintada", com os músculos e ossos sem os detalhes importantes, que facilitariam a compreensão; 2. Não havia comentários sobre a respiração ofegante, quando se faz esforço, ou sobre a diferença de desgaste sentida ao se realizar atividades físicas dentro e fora d'água e 3. Deveria ser acrescentado ao livro informações sobre como se conta as pulsações e o seu significado em termos de pressão arterial, na medida em que aprenderam como fazê-lo, com o professor de Educação Física. Ao longo da leitura, os alunos percebiam alguns termos desconhecidos, como tônus muscular e junta óssea. Assim, tomaram a iniciativa de pesquisar, em diferentes fontes de informações, sobre o sistema locomotor, a fim de complementar as informações do livro didático. Consideramos relevante comentar que buscamos evitar situações de memorizações de conceitos, procurando favorecer entre os alunos, entendimentos de fenômenos que acontecem em nosso corpo após esforços físicos dentro e fora da água, inclusive ao trabalharmos com o livro didático, o que só ocorreu após os três primeiros momentos.

Amaral e Megid Neto (1997) e Bizzo (2000) constataram que os erros conceituais e a presença de preconceitos (sociais, culturais, raciais, de gênero) estão presentes em livros didáticos brasileiros de Ciências, podendo ser detectados nos textos, nas atividades e nas ilustrações. Assim, após discutirmos as incoerências, sugerimos, com base nos conhecimentos apreendidos até então, que os alunos classificassem as informações do livro didático em: incorretas, incompletas ou ambíguas, efetivando pesquisas complementares para subsidiar adequações necessárias. Apoiado em Núñez, Ramalho, Silva e Campos (2012), sugerimos que o professor, baseado em suas vivências, envie avaliações aos responsáveis pela editoração de livros, sempre que necessário, para o aprimoramento desse recurso didático. No entanto, é necessário salientar que, apesar desta sugestão de iniciativa, os problemas detectados persistem, na medida em que, no mesmo artigo, Núñez et al. (2012) concluíram que muitos livros excluídos pelo Ministério da Educação e Cultura, atual Ministério da Cultura (MEC) continuam integrando o acervo bibliográfico das escolas.

Notamos, nos quatro momentos de ensino-aprendizagem que os interesses, motivações e curiosidades dos alunos, advindos da exploração de situações escolares e extra-escolares, trouxeram como consequência uma sensibilização da importância de se fazer corretamente uma leitura das suas observações. Os alunos demonstraram entender que para poder inferir suas opiniões sobre o assunto era necessário baseá-las nas diferentes fontes de informações e não apenas se restringir ao livro didático. $O$ fruto desse processo foi a resolução das situações- 
problemas proposta em cada momento e a facilidade que a turma revelou na organização do conteúdo do CD-ROM, como $5^{\circ}$ momento - ao final do ano letivo e sobre todos os conteúdos relativos ao corpo humano estudados-, no qual tivemos apoio da professora de informática, para sua confecção. Consideramos que este momento constituiu-se na culminância das atividades precedentes, apresentando registros das suas realizações e dos saberes elaborados no processo.

Cabe ressaltar que o $5^{\circ}$ momento foi essencial no processo avaliativo qualitativo, pois os alunos partiram da questão norteadora e das questões secundárias que cada equipe buscou responder. Os alunos organizaram os dados obtidos por meio de suas anotações/resumos e outras fontes consultadas. Nesta situação, cada equipe redigiu um texto, com a análise dos resultados e conclusão da pesquisa. Alguns alunos expressaram sua dificuldade com esta etapa: "Professora, como é que se escreve um texto com as nossas palavras, se a gente leu tanta coisa?"; "É complicado ter que escrever o que a gente acha depois de ler tanto!" Por estes depoimentos, percebemos que os alunos não estão habituados a produzir textos nos quais é necessário demonstrar o conhecimento adquirido, após consultas a fontes variadas.

Neste contexto, concordando com Ferreira (1998), buscamos favorecer no alunado a conscientização de que recursos tecnológicos, por mais sofisticados que sejam, não representam um fim em si mesmo, nem substituem raciocínios e reflexões, fatores essenciais para aprendizagens significativas; podem, no entanto, constituírem ótimas ferramentas para apreensões, registros e apresentações de detalhes acessíveis aos órgãos sensoriais; em nosso caso, imagens, som e funções do sistema locomotor. A satisfação e a autoconfiança quanto à aprendizagem foi traduzida pela fala: "Com o nosso CD-ROM, as pessoas vão aprender junto com a gente!" Convém pontuar que a produção discente foi apresentada à Escola e à comunidade atendida, em uma palestra, na qual os próprios alunos interagiram com a plateia, explicando seu trabalho, esclarecendo detalhes e dirimindo dúvidas.

Cabe ressaltar que é de suma importância as interações que se estabelecem entre a escola e a comunidade, pois de acordo com Bezerra et al. (2010, p. 290):

Entendemos que encontrar o caminho para relações de parceria pode ser uma experiência significativa, resultando em melhorias nas interações humanas, no ensino, na preservação das instalações físicas e combate da violência dentro e fora da escola. Pode ser a luz de um novo tempo na educação: o aproveitamento das experiências familiares na construção do saber e das ações da escola (Bezerra et al., 2010, p. 290).

Incorporamos todas as sugestões e críticas à versão final do CD-ROM e, posteriormente, este produto didático passou a integrar o acervo da biblioteca da Escola.

Ao buscarmos evidenciar as interrelações do conteúdo com áreas diversificadas, em conjunto com as diferentes metodologias (o modelo, a visita à academia, a aula na quadra poliesportiva, o boneco Juvenal, releitura do livro didático e a produção do CD-ROM) na abordagem dos assuntos, favorecemos compreensões contextualizadas do sistema locomotor. As reflexões de Buchweitz (2001) e os comentários dos alunos enfatizaram a importância que o vivenciar (experimentar) favoreceu formalizações de indagações e respostas com mais discernimento. É evidente que, ao empregarmos estas metodologias, sentimos incertezas e inseguranças, mas percebemos que o empenho de vivenciar a interdisciplinaridade, buscando integrar os diferentes saberes para perceber o todo, sem desqualificar as especificidades das 
partes, originou um novo saber e, de acordo com Nogueira (2005), a compreensão de que cada área do conhecimento se enriquece quando dialoga com outras, ampliando percepções e vivências.

Após refletirmos acerca de todos os momentos vivenciados, sugerimos a troca de posição do $3^{\circ}$ com o $4^{\circ}$ passo, dos passos de Zylberztajn (1991) para elaboração do conhecimento, como fizemos: valorizando os esforços que os alunos precisam dispensar para a construção de seu aprendizado e finalizando com a apresentação dialogada das concepções científicas. Ressaltamos que nem sempre é fácil agir seguindo esses passos, pois há um conteúdo a ser seguido e uma programação a ser terminada em contraposição a um período muito curto para realizá-los, sem contar outros fatores já citado anteriormente (HENNIG, 1998; SOUZA, 2002; SOUZA et al., 2003; SILVA et al., 2010; DANTAS et al., 2012; SILVA et al., 2012).

No entanto, temos a convicção de que o trabalho cooperativo para efetivar esses passos é essencial e de que sem a participação de outros professores, principalmente os de Educação Física e de Informática, as atividades não teriam apresentado resultados tão eficientes. Ações cooperativas com emprego, contextualizado e integrado, de diferentes saberes estão de acordo com os princípios da interdisciplinaridade no processo de ensino-aprendizagem (FAZENDA, 1993; GIRARDELLI, 1999; BORDONI 2002).

Outro aspecto a ser ressaltado é que em estudo anterior avaliamos as situações experimentais olhando "de fora" o processo educacional, em uma análise quantitativa, por meio de notas creditadas aos alunos, mas não consideramos essa forma satisfatória, pois avaliar valorizando apenas parte do desenvolvimento cognitivo do aluno é negar-lhe o desenvolvimento de todas as suas potencialidades.

Assim, neste estudo, mudamos de posição, passando a olhar "de dentro" o processo, analisando a própria experiência do pesquisador, enquanto professor. Nesse sentido, a concepção do professor/pesquisador passa a ser "[...] veículo inteligente e ativo entre o conhecimento acumulado na área e as novas evidências que serão estabelecidas a partir da pesquisa" (LÜDKE; ANDRÉ, 1986, p. 6). Portanto, consideramos esta ressignificação das práticas de pesquisa bastante produtiva tanto para o alunado como para o professor, uma vez que deixou de ser entendida como atividades neutras, baseada na imparcialidade do professor, e passa a ser concebida como multidimensional, situando-se em atividades sociopoliticamente contextualizadas, contendo valores éticos e morais.

\section{CONSIDERAÇÕES FINAIS}

Em vista dos resultados obtidos, acreditamos que o emprego de momentos de atividades sequenciais, tendo como temática o sistema locomotor, constituiu em situações de aprendizagens significativas, afinal, buscamos estimular os alunos a compartilharem dúvidas, opiniões e, literalmente, manusearem para construírem respostas, vinculadas às apreensões dos conteúdos abordados.

Como realizamos a ação avaliativa em todos os momentos de forma dialogada e interativa, e nós, professores, exercendo o papel de mediador entre o aluno e o conhecimento, consideramos que a avaliação foi como uma alavanca para promoção da autonomia e autoconfiança do alunado. E para tanto, o processo de ensino e aprendizagem foi baseado nos princípios da interdisciplinaridade, que facilitaram a apreensão dos conceitos biológicos ao mesmo tempo em que os alunos puderam fazer analogia com assuntos estudados em outras discipli- 
nas escolares, em um processo de aprendizagem retroalimentado envolvendo os conceitos provenientes de várias disciplinas. Acreditamos, no entanto, que este exercício interdisciplinar só foi possível graças ao apoio de toda a comunidade educacional, numa busca conjunta pela melhoria da qualidade do ensino.

Neste contexto, nós, professores também fomos beneficiados, porque a partir da autorreflexão, pudemos aperfeiçoar nossas competências e habilidades, reconhecer aspectos frágeis e buscar os ajustes necessários, para encontrar um ponto de equilíbrio entre interesses do educando e nossos propósitos vinculados ao processo de ensino e aprendizagem.

Concluímos que a função dos conhecimentos pré-existentes dos alunos foi a de dar significado e sustentação para novos, e estes saberes, por sua vez, ao serem internalizados, assumiram a posição e a função de conhecimentos pré-existentes, criando, assim, uma estrutura cognitiva cíclica que se renovou/atualizou/recompôs a cada nova aprendizagem conquistada.

\section{AGRADECIMENTOS}

A CAPES pela concessão da bolsa de mestrado, para a primeira autora desse artigo. Às profas. dras. Maria de Fátima Vilhena da Silva e Maria de Jesus da Conceição Ferreira Fonseca, pelas valiosas contribuições na versão final da dissertação. À Doris Monteiro, professora de informática, pelo auxílio na confecção do CD-ROM. À Moana Luri de Almeida pela versão do resumo para o inglês.

\section{REFERÊNCIAS}

AMARAL, I. A. dos. Conhecimento formal, experimentação e estudo ambiental. Ciência \& Ensino, v.3, p. 10-15, 1997.

AMARAL, I. A.; MEGID NETO, J.. Qualidade do livro didático de Ciências: O que define e quem define? Ciência \& Ensino, n. 2, 13-14, 1997.

ANDRÉ, M.; LÜDKE, M. A pesquisa em educação: abordagens qualitativas. São Paulo: EPU, 1986.

AUSUBEL, D. P. Aquisição e retenção de conhecimentos: uma perspectiva cognitiva, Lisboa: Plátano, 2003.

BACHELARD, G. A formação do espírito científico: contribuição para uma psicanálise do conhecimento. Rio de Janeiro: Contraponto, 1996.

BARNI, M. J.; SCHNEIDER, E. J. (2003). A Educação Física no ensino médio. Relevante ou irrelevante? Instituto Catarinense de Pós Graduação. 2003. Disponível em: <http://www.icpg.com.br>. Acesso em: 26 jun. 2012.

BEZERRA, Z. F. et al.. Comunidade e escola: reflexões sobre uma integração necessária. Educar em Revista, n. 37, p. 279-291, 2010. 
BIASOTTO, C. B., \& GOMES, C. R. G. (2012). Análise postural em escolares do ensino fundamental com programa de prevenção PDE/2008. Recuperado em 26 junho, 2012, de http://www.diaadiaeducacao.pr.gov.br/portals/pde/arquivos/2271-8.pdf.

BIZZO, N.. Falhas no ensino de Ciências. Ciência Hoje, p. 27-31, 2000.

BORDONI, T. C.. Uma postura interdisciplinar. Fórum Educação. 2002. Disponível em: < http://www.forumeducacao.hpg.ig.com.br/textos/textos/didat_7.htm.> Acesso em: 26 jun. 2012.

BOVO, M. C.. Interdisciplinaridade e transversalidade como dimensões da ação pedagógica. Revista Urutágua. 2007. Disponível em: <http://www.urutagua.uem.br//007/07bovo.htm. > Acesso em: 26 jun. 2012.

BRASIL. Ministério da Educação. Secretaria de Educação Fundamental. Parâmetros Curriculares Nacionais: terceiro e quarto ciclos do ensino fundamental: Ciências Naturais. Brasília: MEC/SEF, 2000.

BRASIL. Ministério da Educação e do Desporto. Secretaria de Educação Fundamental. Parâmetros Curriculares Nacionais: ciências naturais. Brasília: MEC/SEF, 2001.

BUCHWEITZ, B. Aprendizagem significativa: idéias de estudantes concluintes de curso superior. Investigações em Ensino de Ciências, v.6, n. 2, p. 133-141, 2001. Disponível em: <http://www.if.ufrgs.br/public/ensino/vol6/n2/v6_n2_a2.htm. > . Acesso em: 26 jun. 2012.

BUENO, A. P. La construcción del conocimiento científico y los contenidos de ciencias. In: ALEIXANDRE, M. P. J. (Coord.) Enseñar ciências. Barcelona: Editorial GRAÓ, 2003. p. 33-54.

CARVALHO, A. M. P.; GIL-PÉREZ, D.. Formação de professores de Ciências. 7. ed. São Paulo: Cortez, 2003.

DANTAS, O. M. S., SANTANA, A. R.; NAKAYAMA, L. Teatro de fantoches na formação continuada docente em Educação Ambiental. Educação e Pesquisa, v.38, n.3, p. 711-726, 2012. Disponível em: <http://www.scielo.br/scielo.php?pid=S151797022012000300012\&script=sci_arttext > Acesso em: 21 dez. 2012.

DELIZOICOV, D., ANGOTTI, J. A., PERNAMBUCO, M. M. Ensino de ciências: fundamentos e métodos. São Paulo: Cortez, 2002.

FAZENDA, I. C. A. Interdisciplinaridade: um projeto em parceria. São Paulo: Loyola, 1993.

FERREIRA, V. As tecnologias interativas no ensino. Química Nova. 1998. Disponível em: $<$ http://www.scielo.br/scielo.php?script=sci_arttext\&pid=S010040421998000600019\&Ing=pt $\&$ nrm=iso $>$ Acesso em: 26 jun.2012.

FONSECA, M. J. C. F.; NAKAYAMA, L. Narrativas para ensinar-aprender a Amazônia: uma contribuição à Educação Ambiental em contextos educacionais diversos. Revista de Estudos Universitários. V. 36, n. 3, p. 143-153, 2010. 
FREIRE, P. Pedagogia da esperança: um reencontro com a Pedagogia do oprimido. 2. ed. São Paulo: Paz e Terra, 1993.

GATTI, B. A.. Formação de professores, pesquisa e problemas metodológicos. Contrapontos, v. 3, n. 3, p. 381-392, 2003.

GIRARDELLI, M. F.. Qual é a diferença entre multidisciplinaridade, interdisciplinaridade e transdisciplinaridade? Nova Escola on-line. 1999. Disponível em: < http://novaescola.abril.com.br/ed/124_ago99/html/comcerteza_didatica.htm > Acesso em: 26 jun. 2012,

HENNIG, G. J. Metodologia do ensino de Ciências. 2. ed. Porto Alegre: Mercado Aberto, 1998.

KRASILCHIK, M. O professor e o currículo de ciências no $\mathbf{1}^{\circ}$ grau. São Paulo: Atual, 1987.

KRASILCHIK, M. Reformas e realidade: o caso do ensino das Ciências. São Paulo em Perspectiva, n. 14, v. 1. Disponível em: 〈http://www.scielo.br/pdf/spp/v14n1/9805.pdf> Acesso em: 26 jun. 2012.

LAJOLO, M.. Livro didático: um (quase) manual de usuário. Em Aberto, n. 69, p. 3-7, 1996.

LIBÂNEO, J. C.. Adeus professor, adeus professora? Novas exigências educacionais e profissão docente. São Paulo: Cortez, 2001.

LÜDKE, M..; ANDRÉ, M.. Pesquisa em educação: abordagens qualitativas. São Paulo: EPU, 1986.

MASSABNI, V. G. (2007). O construtivismo na prática de professores de Ciências: realidade ou utopia? Ciências \& Cognição, v. 10, n. 4, p. 104-114. Disponível em: <http://www.cienciaecognicao.org > Acesso em: 26 jun. 2012.

MEIRIEU, P.. Aprender... Sim, mas como? Porto Alegre: Artmed, 1998.

MINAYO, M. C. S.. Pesquisa social: teoria, método e criatividade. 20. ed. Petrópolis: Vozes, 2002.

NOGUEIRA, N. R.. Pedagogia dos projetos: uma jornada interdisciplinar rumo ao desenvolvimento das múltiplas inteligências. 6.ed. São Paulo: Érica, 2005.

Núñez, I. B. et al. A seleção dos livros didáticos, um saber necessário ao professor: O caso do Ensino de Ciências. 2012. Disponível em: < http://www.darwin.futuro.usp.br > Acesso em: 26 jun. 2012.

PERRENOUD, P. Ensinar: agir na urgência, decidir na incerteza. Porto Alegre: Artmed, 2001. 
SANMARTÍ, N. Didáctica de las ciencias en la educación secundaria obligatoria. Madrid: Sintesis Educación, 2002.

SAVIANI, D.. Educação: do senso comum à consciência filosófica. Campinas: Autores Associados, 2002.

SILVA, L. H.,; ZANON, L. B. A experimentação no ensino de Ciências. In: SCHNETZLER, R..; ARAGÃO, R. M. R.. Ensino de Ciências: fundamentos e abordagens Piracicaba: CAPES/UNIMEP, 2000. p. 120-153.

Silva, L. C. et al.. Projeto Sábado Esperto: Educação Ambiental no Bosque Rodrigues Alves Jardim Botânico da Amazônia, Belém - PA. Educação Ambiental em Ação, v. 40, p. 1-15, 2002. Disponível em: <http://www.revistaea.org/ >. Acesso em: 21 dez. 2012.

SILVA, F. S. et al. . Educação Ambiental: olhares e propostas no município de Rondon do Pará. Revista Eletrônica do Mestrado em Educação Ambiental. n. 24, p.1-11, 2010. Disponível em: < http://www.remea.furg.br/indvol24.php.> Acesso em: 26 jun.2012.

SOUSA, C. P.. Avaliação do rendimento escolar. 3.ed. Campinas: Papirus, 2002.

SOUZA, S. P.. Atividades práticas: estratégias e avaliações para o ensino-aprendizagem em Ciências. Trabalho de Conclusão de Curso (Licenciatura Plena em Biologia), Universidade Federal do Pará, Belém, 2002.

SOUZA, S. P., NAKAYAMA, L., BELÚCIO, L. F.. Atividades práticas: um valioso instrumento no ensino fundamental. Participação - Revista do Decanato de Extensão da Universidade de Brasília, v. 7, n.12, p. 33-36, 2003.

THIOLLENT, M.. Metodologia da pesquisa-ação. 14a ed.. São Paulo: Cortez, 2005.

TOZONI-REIS, M. F. C.. A pesquisa-ação-participativa em educação ambiental: reflexões teóricas. São Paulo: Annablume, 2007.

VASCONCELLOS, C. S. A construção do conhecimento em sala de aula. São Paulo: Cadernos Pedagógicos do Libertad, 1994.

ZYLBERZTAJN, A... Revoluções científicas: ciência normal na sala de aula. In: MOREIRA, M. A Tópicos em Ensino de Ciências. Porto Alegre: Sagra, 1991. 